\title{
ANALISIS MUTU PELAYANAN TERHADAP KEPUASAN PASIEN DI RUMAH SAKIT PERTAMINA BINTANG AMIN BANDAR LAMPUNG TAHUN 2018
}

\author{
Ratna Purwaningrum ${ }^{1}$ \\ ${ }^{1}$ Departemen Histologi, Fakultas Kedokteran Universitas Malahayati
}

\begin{abstract}
Service Quality Analysis On Patients Satisfaction In Pertamina Bintang Amin Hospital Bandar Lampung 2018. The researcher's observation during the preliminary study in the inpatient room of Pertamina Bintang Amin Hospital obtained result that there were patients who were not really satisfied with the nurse's performance in 2017. It was known that there was an effect of service quality on patients' satisfaction in Pertamina Bintang Amin Hospital of Bandar Lampung 2018. The research was quantitative through cross sectional approach. The research was done in June - July 2018 in Pertamina Bintang Amin Hospital of Bandar Lampung. The population was all patients who obtained health care for two days in the hospital in June 2018 , totaling in 65 people as the sample. The research result of the patients' characteristics as the respondents in the hospital in 2018 obtained that most of the were aged between 40-51 years old amounting to 69 people $(57.5 \%)$, respondents were male amounting to 74 people $(61.7 \%)$, respondents has low education amounting to 82 people $(68.3 \%)$, and respondents has job amounting to 84 people (70\%). Most of the respondents were satisfied as many as 73 people $(60.8 \%)$. For the dimension of the health service, reliability was 73 people $(60.8 \%)$, assurance was 65 people (54.2\%), tangible was 69 people $(57.5 \%)$, empathy was 64 people $(53.3 \%)$, responsiveness was 61 people $(50.8 \%)$. The relationship between the dimension of health service with the patients' satisfaction of the reliability by $p$-value of 0.002 , assurance by $p$-value of 0.001 , tangible by $p$-value of 0.014 , empathy by $p$-value of 0.037 and responsiveness by $\mathrm{p}$-value of 0.006 . The most dominant variable to patients' satisfaction is empathy.
\end{abstract}

Keywords: Health Service, Hospital, Satisfaction

\begin{abstract}
Abstrak: Analisis Mutu Pelayanan Terhadap Kepuasan Pasien Di Rumah Sakit Pertamina Bintang Amin Bandar Lampung Tahun 2018. Hasil pengamatan peneliti selama melakukan studi pendahuluan diruang rawat inap RS. Pertamina Bintang Amin dijumpai adanya pasien menyatakan kurang puas dengan pelayanan perawat di Rs. Pertamina Bintang Amin pada tahun 2017 dan pada tahun 2018 banyaknya komplain yang dikirim melalui manajemen bisnis RSPBA 2018. Jenis penelitian kuantitatif, pendekatan cross sectional. Waktu penelitian pada bulan Juni - Juli 2018, tempat penelitian adalah RS. Pertamina Bintang Amin Bandar Lampung. Populasi seluruh pasien yang menjalani perawatan selama 2 hari di RS. Pertamina Bintang Amin Bandar Lampung pada bulan Juni 2018, sampel 65 orang. Hasil penelitian karakteristik responden pasien di RS. Pertamina Bintang Amin Bandar Lampung tahun 2018 responden berumur 41 - 50 tahun berjumlah 69 orang $(57,5 \%)$, berjenis kelamin laki - laki berjumlah 74 orang $(61,7 \%)$, berpendidikan rendah berjumlah 82 orang $(68,3 \%)$ dan responden yang mempunyai pekerjaan berjumlah 84 orang (70\%). Sebagian besar puas berjumlah 73 orang $(60,8 \%)$. Dimensi pelayanan kesehatan reliability 73 orang $(60,8 \%)$, assurance 65 orang $(54,2 \%)$, tangible 69 orang $(57,5 \%)$, empathy 64 orang $(53,3 \%)$, responsiviness 61 orang $(50,8 \%)$, keterkaitan antara dimensi mutu pelayanan kesehatan dengan kepuasan pasien reliability $p$ - value 0,002 , assurance $p$ - value 0,001, tangible $p$ - value 0,014, empathy $p$ - value 0,037, responsiveness $p$ - value 0,006 . Variabel empati paling dominan terkait dengan kepuasan pasien.
\end{abstract}

Kata kunci : Kepuasan, Mutu Pelayanan, Rumah Sakit 


\section{PENDAHULUAN}

Era globalisasi telah menjanjikan suatu peluang dan tantangan bisnis baru bagi rumah sakit yang beroperasi di Indonesia. Di satu sisi era globalisasi memperluas pasar baik produk atau jasa dari rumah sakit di Indonesia dan di sisi lain keadaan tersebut memunculkan persaingan yang semakin ketat baik antar rumah sakit domestik maupun dengan rumah sakit asing. Pesatnya pertumbuhan ekonomi serta tantangan era perdagangan menyebabkan semakin ketatnya kompetisi dalam dunia bisnis, begitu juga dengan bisnis dalam pelayanan kesehatan khususnya rumah sakit, yang dituntut untuk dapat memenuhi kebutuhan dan keinginan pelanggan yang tidak hanya terbatas pada pelayanannya saja (Tjiptono, 2011).

Menurut WHO, rumah sakit adalah suatu bagian menyeluruh dari organisasi sosial dan medis berfungsi memberikan pelayanan kesehatan yang lengkap kepada masyarakat, baik kuratif maupun rehabilitatif, rumah sakit juga merupakan pusat latihan tenaga kesehatan, serta untuk penelitian biososial. Setiap fasilitas pelayanan kesehatan mempunyai kewajiban untuk memberikan pertanggungjawaban atas pelayanan yang telah diberikan (Budi, 2011).

Rumah sakit dinyatakan berhasil, tidak hanya pada pelayanan yang diunggulkan, melainkan juga sikap dan layanan sumber daya manusia merupakan elemen yang berpengaruh terhadap pelayanan yang dihasilkan kepada pasien. Bila elemen tersebut diabaikan maka dalam waktu yang tidak lama, rumah sakit akan kehilangan banyak pasien yang dijauhi oleh calon pasien. Pasien akan beralih ke rumah sakit lainnya yang memenuhi harapan pasien, hal itu dikarenakan pasien merupakan asset yang sangat berharga dalam mengembangkan industri rumah sakit (Anjaryani, 2009).

Setiap pelayanan yang diberikan oleh rumah sakit berpengaruh pada tingkat kepuasan pasien. Kepuasan pelanggan yang dalam hal ini adalah pasien dipengaruhi oleh mutu pelayanan kesehatan yang adalah suatu pencapaian hasil yang optimal untuk setiap pasien, terhindarnya pasien dari komplikasi akibat tindakan petugas kesehatan dan perhatian terhadap kebutuhan pasien dan keluarganya dengan upaya yang memperhatikan efektivitas biaya serta terekam dalam suatu dokumentasi yang masuk akal (Hatta, 2009).

Hakikat dasar dari rumah sakit adalah pemenuhan kebutuhan dan tuntutan pasien yang mengharapkan penyelesaian masalah kesehatannya pada rumah sakit. Pasien memandang bahwa hanya rumah sakit yang mampu memberikan pelayanan medis sebagai upaya penyembuhan dan pemulihan atasrasa sakit yang dideritanya. Pasien mengharapkan pelayanan yang siap, cepat, tanggap dan nyaman terhadap keluhan penyakit pasien. Dalam memenuhi kebutuhan pasien tersebut, pelayanan prima menjadi utama dalam pelayanan di Rumah Sakit. Pelayanan prima di rumah sakit akan tercapai jika setiap seluruh SDM rumah sakit mempunyai keterampilan khusus, diantaranya memahami produk secara mendalam, berpenampilan menarik, bersikap ramah dan bersahabat, responsif (peka) dengan pasien, menguasai pekerjaan, berkomunikasi secara efektif dan mampu menanggapi keluhan pasien secara profesional (Anjaryani, 2009).

Strategi pelayanan prima bahwa setiap rumah sakit harus melakukan pendekatan mutu paripurna yang berorientasi pada kepuasan pasien, agar Rumah Sakit tetap eksis, di tengah pertumbuhan industri pelayanan kesehatan yang semakin kuat. Upaya rumah sakit untuk tetap bertahan dan berkembang adalah dengan meningkatkan pelayan kepada pasien. Hal tersebut karena pasien merupakan sumber pendapatan yang ditunggu oleh rumah sakit, baik secara langsung (out of pocket) maupun secara tidak langsung melalui asuransi kesehatan. Tanpa pasien, rumah sakit tidak dapat bertahan dan berkembang mengingat besarnya biaya operasional rumah sakit yang tinggi. Rumah sakit 
melakukan berbagai cara untuk meningkatnya kunjungan pasien, sehingga dari dampak yang muncul akan menimbulkan sebuah loyalitas pada pasien sehingga pasien akan datang kembali memanfaatkan jasa rumah sakit tersebut (Muninjaya, 2014).

Kepuasan pasien tergantung pada kualitas pelayanan. Pelayanan adalah semua upaya yang dilakukan karyawan untuk memenuhi keinginan pelanggannya dengan jasa yang akan diberikan. Suatu pelayanan dikatakan baik oleh pasien, ditentukan oleh kenyataan apakah jasa yang diberikaan bisa memenuhi kebutuhan pasien, dengan menggunakan persepsi pasien tentang pelayanan yang diterima (memuaskan atau mengecewakan, juga termasuk lamanya waktu pelayanan). Kemenkes yang bekerja sama dengan Komite Akreditasi Rumah Sakit (KARS) menetapkan standar mutu pelayanan, agar semua Rumah Sakit terakreditasi minimal 5 pelayanan, yaitu: pelayanan gawat darurat, pelayanan medik, pelayanan administrasi, pelayanan keperawatan dan pelayanan rekam medik.

Kualitas dan kepuasan tidak dapat dipisahkan seperti layaknya dua sisi mata uang yang saling berhubungan dan mempengaruhi. Kualitas memberikan suatu dorongan kepada pasien untuk menj alin hubungan yang kuat dengan rumah sakit. Hubungan seperti ini dalam jangka panj ang memungkinkan rumah sakit untuk memahami dengan seksama kebutuhan dan harapan pasien. Dengan demikian, rumah sakit dapat meningkatkan kepuasan pasien di rumah sakit melalui pengalaman pasien yang menyenangkan dan meminimalkan atau meniadakan pengalaman yang kurang menyenangkan. Kepuasan pasien pada akhimya berpengaruh terhadap kesetiaan pasien kepada rumah sakit yang memberikan kualitas yang memuaskan (Nursalam, 2016).

Hasil pengamatan peneliti selama melakukan studi pendahuluan diruang rawat inap RS. Pertamina Bintang Amin dijumpai adanya pasien menyatakan kurang puas dengan pelayanan perawat di Rs. Pertamina Bintang Amin pada tahun 2017 dan pada tahun 2018 banyaknya komplain yang dikirim melalui manajemen bisnis RSPBA 2018. Pelaksanaan misi pelayanan medis dan sistem kerja yang terstandar belum berjalan optimal, hal ini terlihat pada data rekam medis pada bulan desember 2017 menunjukan BOR $(64,45 \%)$, LOS $(2,50)$, BTO $(7,99)$ dan TOI $(1,38)$ angka tersebut menunjukan masih belum mencapai standar Kemenkes tahun 2010 yaitu $\mathrm{BOR}=70-$ $85 \%, \mathrm{BTO}=5-45$ hari/ tahun, $\mathrm{TOI}=1-3$ hari tempat tidur yang kosong, LOS= 7-20 hari.

\section{METODE}

Penelitian ini telah dilaksanakan di RS. Pertamina Bintang Amin Bandar Lampung pada bulan Juni - Juli 2018. Adapun yang menjadi objek penelitian ini adalah seluruh pasien yang menjalani perawatan selama 2 hari di RS Pertamina Bintang Amin pada bulan Juni-Juli 2018, hal tersebut bertujuan untuk mengetahui keterkaitan antara dimensi mutu pelayanan yang meliputi Reliability, Assurance, tangiable, Emphaty dan Responsiveness terhadap kepuasan pasien yang telah dilakukan. Dengan menggunakan pendekatan cross sectional.

\section{HASIL}

Berdasarkan tabel 1 di bawah diperoleh data kepuasan pasien di RS. Pertamina Bintang Amin Bandar Lampung tahun 2018 sebagian besar puas berjumlah 73 orang $(60,8 \%)$. Pada data Reliability di RS. Pertamina Bintang Amin Bandar Lampung tahun 2018 sebagian besar baik berjumlah 73 orang $(60,8 \%)$. Pada data Assurance di RS. Pertamina Bintang Amin Bandar Lampung tahun 2018 sebagian besar baik berjumlah 65 orang (54,2\%). Pada data Tangible di RS. Pertamina Bintang Amin Bandar Lampung tahun 2018 sebagian besar baik berjumlah 69 orang $(57,5 \%)$. Pada data Empathy di RS. Pertamina Bintang Amin Bandar Lampung tahun 2018 sebagian besar 
baik berjumlah 64 orang (53,3\%).

Pada data responsiviness di RS.

Pertamina Bintang Amin Bandar
Lampung tahun 2018 sebagian besar

baik berjumlah 61 orang $(50,8 \%)$.

Tabel 1. Hasil Analisis Univariat

\begin{tabular}{cccc}
\hline Variabel & Kategori & Frekuensi & Persentase (\%) \\
\hline \multirow{2}{*}{ Kepuasan Pasien } & Puas & 73 & 60,8 \\
\cline { 2 - 4 } & Tidak Puas & 47 & 39,2 \\
\cline { 2 - 4 } Reliability & Baik & 73 & 60,8 \\
\cline { 2 - 4 } & Tidak Baik & 47 & 39,2 \\
\hline \multirow{2}{*}{ Assurance } & Baik & 65 & 54,2 \\
\cline { 2 - 4 } & Tidak Baik & 55 & 45,8 \\
\hline \multirow{2}{*}{ Tangible } & Baik & 69 & 57,5 \\
\cline { 2 - 4 } & Tidak Baik & 51 & 42,5 \\
\hline \multirow{2}{*}{ Empathy } & Baik & 64 & 53,3 \\
\cline { 2 - 4 } & Tidak Baik & 56 & 46,7 \\
\cline { 2 - 4 } Responsivenes & Baik & 61 & 49,8 \\
\cline { 2 - 4 } & Tidak Baik & 59 &
\end{tabular}

Berdasarkan uji statistik Chi Square pada tabel 2 di bawah didapatkan $\boldsymbol{\rho}$ value 0,002 dengan tingkat kepercayaan 0,05 sehingga $\boldsymbol{\rho}$ value $<a$ $(0,002<0,05)$ yang berarti ada hubungan Reliability dengan kepuasan pasien di RS. Pertamina Bintang Amin Bandar Lampung tahun 2018 dan diperoleh pula $O R=3,11$ yang berarti perawat dengan Reliability baik mempunyai peluang 3,11 kali lebih besar dalam meningkatkan kepuasan pasien dibanding perawat dengan Reliability tidak baik. Berdasarkan uji statistik Chi Square didapatkan $\boldsymbol{\rho}$ value 0,001 dengan tingkat kepercayaan 0,05 sehingga $\boldsymbol{\rho}$ value $<a$

\section{Tabel 2. Hasil Analisis Bivariat}

\begin{tabular}{|c|c|c|c|c|c|c|c|c|c|}
\hline \multirow{3}{*}{ Variabel } & \multirow{3}{*}{ Kategori } & \multicolumn{4}{|c|}{ Kepuasan Pasien } & \multirow{2}{*}{\multicolumn{2}{|c|}{ Total }} & \multirow{3}{*}{$\begin{array}{c}\rho . \\
\text { Value }\end{array}$} & \multirow{3}{*}{$\begin{array}{c}\text { OR } \\
\text { CI } \\
95 \% \\
\end{array}$} \\
\hline & & \multicolumn{2}{|c|}{ Puas } & \multicolumn{2}{|c|}{ Tidak } & & & & \\
\hline & & $\mathbf{n}$ & $\%$ & $\mathbf{n}$ & $\%$ & $\mathbf{n}$ & $\%$ & & \\
\hline \multirow{2}{*}{ Reliability } & Baik & 53 & 72,6 & 20 & 27,4 & 73 & 100 & \multirow{2}{*}{0,002} & \multirow[b]{2}{*}{3,578} \\
\hline & Tidak Baik & 20 & 42,6 & 27 & 57,4 & 47 & 100 & & \\
\hline \multirow{2}{*}{ Assurance } & Baik & 49 & 75,4 & 16 & 24,6 & 65 & 100 & \multirow{2}{*}{0,001} & \multirow{2}{*}{3,95} \\
\hline & Tidak Baik & 24 & 43,6 & 31 & 56,4 & 55 & 100 & & \\
\hline \multirow[b]{2}{*}{ Tangible } & Baik & 49 & 71,0 & 20 & 29,0 & 69 & 100 & \multirow[b]{2}{*}{0,014} & \multirow[b]{2}{*}{2,75} \\
\hline & Tidak Baik & 24 & 47,1 & 27 & 52,9 & 51 & 100 & & \\
\hline \multirow[b]{2}{*}{ Empathy } & Baik & 45 & 70,3 & 19 & 29,7 & 64 & 100 & \multirow[b]{2}{*}{0,037} & \multirow[b]{2}{*}{2,368} \\
\hline & Tidak Baik & 28 & 50,0 & 28 & 50,0 & 56 & 100 & & \\
\hline \multirow[b]{2}{*}{ Responsivines } & Baik & 45 & 73,8 & 16 & 26,2 & 61 & 100 & \multirow[b]{2}{*}{0,006} & \multirow[b]{2}{*}{3,11} \\
\hline & Tidak Baik & 28 & 47,5 & 31 & 52,5 & 59 & 100 & & \\
\hline
\end{tabular}

$(0,001<0,05)$ yang berarti ada hubungan Assurance dengan kepuasan pasien di RS. Pertamina Bintang Amin
Bandar Lampung tahun 2018 dan diperoleh pula $\mathrm{OR}=3,95$ yang berarti perawat dengan Assurance baik 
mempunyai peluang 3,95 kali lebih pasien dibanding perawat dengan Assurance tidak baik. Berdasarkan uji statistik Chi Square didapatkan $\boldsymbol{\rho}$ value 0,014 dengan tingkat kepercayaan 0,05 sehingga $\boldsymbol{\rho}$ value $<\mathrm{a}(0,014<$ $0,05)$ yang berarti ada hubungan Tangible dengan kepuasan pasien di RS. Pertamina Bintang Amin Bandar Lampung tahun 2018 dan diperoleh pula $\mathrm{OR}=2,75$ yang berarti perawat dengan Tangible baik mempunyai peluang 2,75 kali lebih besar dalam meningkatkan kepuasan pasien dibanding perawat dengan Tangible tidak baik.

Berdasarkan uji statistik Chi Square didapatkan $\boldsymbol{\rho}$ value 0,037 dengan tingkat kepercayaan 0,05 sehingga $\boldsymbol{\rho}$ value $<$ a $(0,037<0,05)$ yang berarti ada hubungan Empathy dengan kepuasan pasien di RS. Pertamina Bintang Amin Bandar Lampung tahun 2018 dan diperoleh pula $\mathrm{OR}=3,11$ yang berarti perawat dengan Empathy baik mempunyai peluang 3,11 kali lebih besar dalam meningkatkan kepuasan pasien dibanding perawat dengan Empathy tidak baik. besar dalam meningkatkan kepuasan Berdasarkan uji statistik Chi Square didapatkan $\boldsymbol{\rho}$ value 0,006 dengan tingkat kepercayaan 0,05 sehingga $\boldsymbol{\rho}$ value $<$ a $(0,006<0,05)$ yang berarti ada hubungan responsivines dengan kepuasan pasien di RS. Pertamina Bintang Amin Bandar Lampung tahun 2018 dan diperoleh pula OR $=3,11$ yang berarti perawat dengan responsivines baik mempunyai peluang 3,11 kali lebih besar dalam meningkatkan kepuasan pasien dibanding perawat dengan responsivines tidak baik.

Berdasarkan tabel di bawah model multivariat tahap III ternyata variabel yang memiliki nilai $p$-value $<0.005$ yaitu variabel Reliability ( $p$ - value: 0.013 OR: 3.095), Assurance ( $p$ value: 0.005 OR: 3.594) dan Emphaty ( $p$-value: 0.004 OR: 3.733). Sehingga dapat disimpulkan bahwa variabel Empathy merupakan variabel dominan yang berhubungan dengan kepuasan setelah dikontrol oleh variabel Reliability dan Assurance.

Tabel 3. Hasil Analisis Multivariat dengan Uji Regresi Logistik

\begin{tabular}{lcccc}
\hline \multirow{2}{*}{ Variabel } & \multirow{2}{*}{ Sig. } & \multirow{2}{*}{ OR } & \multicolumn{2}{c}{ 95\% C.I.for EXP(B) } \\
\cline { 4 - 5 } & & & Lower & Upper \\
\hline Reliability & 0,013 & 3,095 & 1,268 & 7,553 \\
\hline Assurance & 0,005 & 3,594 & 1,485 & 8,697 \\
\hline Tangible & 0,079 & 2,242 & 0,911 & 5,514 \\
\hline Emphaty & 0,004 & 3,733 & 1,525 & 9,137 \\
\hline Responsivenes & 0,064 & 2,337 & 0,953 & 5,732 \\
\hline
\end{tabular}

\section{PEMBAHASAN}

$\begin{array}{rr}\text { Menurut } & \text { Parasuraman, } \\ \text { (1990 dalam } & \text { Muninjaya, } \\ \text { Reliability/Kehandalan } & \text { adalah }\end{array}$ kemampuan memberikan layanan yang dijanjikan dengan segera, akurat dan memuaskan. Reliability/ Keterandalan yang merupakan kemampuan untuk menunjukkan layanan yang diharapkan, bisa diandalkan secara akurat. Kehandalan berkaitan dengan kemampuan staf medis rumah sakit untuk memberikan atau menampilkan pelayanan sesuai dengan harapan dan tepat. Hal ini merupakan bagian inti pelayanan medik yaitu kelayakan, efektivitas yang bermanfaat bagi pasien yang dilayani, agar dapat memberikan kesembuhan sebagaimana yang diharapkan oleh pasien yang mendapat petugas kesehatan. Sehubungan dengan aspek Kehandalan, tentunya Pasien mempunyai harapan pihak rumah sakit 
bersama staf medisnya handal dan mampu dalam memberikan layanan yang dijanjikan secara meyakinkan dan akurat atau menampilkan pelayanan sesuai dengan harapan dan tepat (Hasibuan, 2013).

Pengaruh aspek pengetahuan dan kompetensi tentunya tidak terlepas dari sumber daya aparat yang tentunya sangat berperan besar dalam mengembangkan rumah sakit ataupun maju mundurnya rumah sakit. Melihat begitu besarnya peran sumber daya aparat, sampai-sampai timbul suatu pendapat bahwa tanpa peran sumber daya manusia dalam suatu organisasi, maka organisasi tersebut tinggal menghitung hari (tereliminasi). Jadi sumber daya manusia merupakan sumber daya yang paling tinggi dalam organisasi, dibanding dengan sumber daya yang lainnya (Assaf, 2009).

Menurut Parasuraman, dkk, (1990 dalam Muninjaya, 2014), bahwa: Bukti fisik (Tangibles) meliputi fasilitas fisik, perlengkapan, pegawai dan sarana komunikasi. Bukti fisik/Tangibles adalah: Tampilan fisik, fasilitas fisik, peralatan dan keberadaan dari korespondensi personalia. Tampilan Fisik adalah: ketersediaan fasilitas fisik peralatan dan bentuk atau keadaan yang ada hubungan dengan personal, merupakan sesuatu hal yang dapat memberikan kenyamanan bagi pasien yang dilayani oleh dokter dan petugas kesehatan serta staf lainnya.

Penyelenggaraan pelayanan tidak dapat dipisahkan dengan ketersediaan sarana dalam penyelenggaraannya sehubungan dengan tampilan fisik dalam perwujudan kualitas pelayan kesehatan yang dapat dilihat pada ketersediaan peralatan dan keadaan hubungan personal. Ketersediaan sarana merupakan tanggung jawab manajemen RS. Pertamina Bintang Amin selaku pemberi layanan kesehatan dalam memenuhi kebutuhan akan sarana dan prasarana yang ada.

Menurut Parasuraman, dkk, dalam Muninjaya (2014), bahwa Empati (Empathy) meliputi: Kesediaan memberikan perhatian yang mendalam dan khusus kepada masing-masing pelanggan. Hal ini berarti Empati/Empaty, merupakan kemudahan dalam menjalin relasi, komunikasi yang baik, perhatian pribadi dan pemahaman atas kebutuhan individual para pelanggan. Empati berupa Petugas kesehatan/Kepedulian atau perhatian individu yang disediakan oleh dokter dan stafnya untuk melayani pasien. Empati setidaknya akan terlihat dari sikap para medis melalui kemudahan untuk dihubungi, pemberian pelayanan secara cepat, penanganan keluhan pasien secara cepat, mengutamakan sikap ramah dan sopan kepada pasien maupun masyarakat umum yang berada di rumah sakit.

Keluhan pasien ketika mereka merasakan adanya kesenjangan yang terjadi antara kualitas pelayanan yang diharapkan dengan kenyataan yang dilakukan oleh para medis perlu untuk direspon para medis melalui tindakan pelayanan yang dalam sikapnya, para medis mampu memperlihatkan dan mencerminkan standar kualitas pribadi dihadapan masyarakat. Mengedepankan rasa tanggung jawab terhadap kelangsungan pelayanan publik, melalui pemahamannya pada nilai, norma, moral, dan kondisi sosial. Sikap atas pelayanan ini tidak dapat dipisahkan dari kemampuan untuk memenuhi pelayanan sesuai dengan yang telah ditetapkan (Assaf, 2009).

Keluhan pasien ketika mereka rasakan adanya kesenjangan yang terjadi antara kualitas pelayanan yang diharapkan dengan kenyataan yang dilakukan oleh para medis, yaitu: Sikap para medis yang kaku, tidak sopan, menyalahgunakan kekuasaan, tidak adil, diskriminatif sebagai aspek penilaian mutu yang sering dihadapi oleh masyarakat dalam menerima layanan. Secara umum empati harus diakui berkaitan dengan sikap seseorang dalam berperilaku. Sikap dan perhatian para medis, berlaku adil pada setiap pasien maupun berpenampilan baik dalam memberikan perhatian secara individu kepada pasien. Oleh karenanya dalam merespon prinsip-prinsip pelayanan publik yang perlu dipedomani oleh 
segenap para medis selaku pelaksana pelayanan, maka kiranya perlu disertai pula oleh sikap dan perilaku yang santun, keramahtamahan dari para pemberi layanan / para medis baik dalam cara menyampaikan sesuatu yang berkaitan dengan prosedur penanganan, maupun dalam hal ketersediaan petugas, obat-obatan, sarana rumah sakit maupun waktu pelayanan. Hal ini dimungkinkan agar layanan tersebut dapat memuaskan pasien dan merupakan juga suatu terapi pikiran guna menunjang proses penyembuhan.

Responsiveness tentunya tidak terlepas juga dengan layanan inti medis yang merupakan aspek-aspek utama medis dari pelayanan: kecocokan, keefektivitasan dan keuntungan bagi pasien. Hal ini merupakan bagian inti pelayanan medik yaitu kelayakan, efektivitas yang bermanfaat bagi pasien yang dilayani, agar dapat memberikan kesembuhan sebagaimana yang diharapkan oleh pasien yang mendapat petugas kesehatan.

Maka sehubungan dengan aspek Daya Tanggap, Pasien mempunyai harapan bagi para medis untuk mempunyai kemampuan menyediakan jasa tambahan, kemampuan memberikan pelayanan kesehatan bagi pasien agar dapat dilakukan secara cepat, sehingga pasien memperoleh pelayanan sesuai dengan kebutuhan dan harapan. Hal ini dapat diwujudnyatakan dalam penyediaan jasa pada waktu yang telah dijanjikan, dokter bisa ditelepon oleh pasien, ketaatan mengikuti jadwal janjian dengan pasien.

Perwujudan kemampuan dan kesigapan para medis dalam menanggapi keluhan atau masalah dari masyarakat mencerminkan daya tanggap yang dimiliki oleh para medis. Pencapaian kualitas kesehatan ditentukan oleh adanya peranan penting para medis dalam memberikan pelayanan, mendengarkan keluhan, memberikan pemahaman dan pengertian kepada masyarakat mengenai pentingnya kesehatan bagi kehidupan disaat ini dan masa mendatang. Kesigapan para medis menangani keluhan pasien kelas tiga dapat memperlihatkan kelayakannya, terutama mengenai kerjasama yang memudahkan bagi terciptanya keberhasilan pelayanan kesehatan yang lebih baik, dan juga dalam menanggapi permasalahan yang memerlukan respon cepat. Dengan demikian, kepekaan terhadap setiap pelayanan kesehatan, akan memberikan kontribusi positif bagi kualitas kegiatan administrasi dalam menangani pasien dan pelayanan kesehatan pada umumnya. Maka daya tanggap dalam meningkatkan kualitas pelayanan kesehatan menjadi moment atau saat yang menentukan bagi terciptanya jaminan pelayanan kesehatan yang berkualitas (Assaf, 2009).

Secara normatif Undang-Undang no 23/1992 yang kemudian di ganti dengan UU 36/2009 tentang kesehatan dimana berisi bahwa setiapn orang mempunyai hak yang sama dalam memperoleh akses atau sumber daya dibidang kesehatan dan memperoleh pelayanan kesehatan yang aman, bermutu dan terjangkau. Kesehatan merupakan salah satu unsur kesejahteraan umum yang harus diwujudkan sesuai dengan cita-cita bangsa Indonesia. Ditegaskan juga bahwa pembangunan kesehatan diarahkan untuk mempertinggi derajat kesehatan yang besar bagi pengembangan dan pembinaan sumber daya manusia. Dalam konteks perwujudan ini yaitu derajat kesehatan diselenggarakan upaya pelayanan kesehatan dengan pendekatan pemeliharaan, peningkatan kesehatan, pencegahan penyakit, penyembuhan penyakit dan pemulihan penyakit yang dilaksanakan secara menyeluruh, terpadu dan berkesinambungan.

Penelitian ini sejalan dengan teori yang dikemukakan oleh Nursalam (2016) empati yaitu membina hubungan dan perhatian secara individual yang diberikan perusahaan kepada pelanggan seperti mendengarkan keluhan konsumen, 
kemudahan konsumen untuk menghubungi perusahaan, kemampuan petugas kesehatan untuk berkomunikasi dengan konsumen/pelanggan dan usaha perusahaan untuk memahami kebutuhan pelanggannya. Empati dalam suatu pelayanan adalah adanya suatu perhatian, keseriusan, simpatik, pengertian dan keterlibatan pihakpihak yang berkepentingan dengan pelayanan untuk mengembangkan dan melakukan aktivitas pelayanan sesuai dengan tingkat pengertian dan pemahaman dari masing-masing pihak tersebut. Pihak yang memberi pelayanan harus memiliki empati memahami masalah dari pihak yang ingin dilayani. Pihak yang dilayani seyogyanya memahami keterbatasan dan kemampuan orang yang melayani, sehingga keterpaduan antara pihak yang melayani dan mendapat pelayanan memiliki perasaan yang sama.

Dimensi Empati (Empathy) artinya, memberikan perhatian yang tulus kepada pasien yang bersifat individual atau pribadi yang berupaya dalam memahami keinginan pasien (Asmuji, 2013). Persepsi empati merupakan bagian dari dimensi Empati dengan metode SERVEQUAL (Service Quality) yang dikembangkan oleh Parasuraman, Zeithaml dan Malholtra (2005) yang meliputi kemudahan untuk menghubungi perusahaan, kemampuan karyawan untuk berkomunikasi dengan pelanggan dan usaha perusahaan untuk memahami kebutuhan pelanggannya. hasil ini di dukung oleh pendapat dari Raffi (2010) empati merupakan pelayanan yang diharapkan pasien yang meliputi hubungan petugas kesehatan - pasien terjaga dengan baik hal ini sangat penting karena dapat membantu dalam keberhasilan penyembuhan dan peningkatan kesehatan pasien.

Hasil penelitian ini sejalan dengan penelitian yang telah dilakukan oleh Lawalata (2016) dengan judul hubungan antara mutu pelayanan dengan kepuasan pasien di ruang rawat inap penyakit dalam RSU
Bethesda GMIM Tomohon. Berdasarkan hasil penelitian terdapat hubungan antara keandalan dengan kepuasan pasien dan ada hubungan antara perhatian dengan kepuasan pasien di ruang rawat inap RSU Bethesda GMIM Tomohon. Begitupula dengan penelitian yang telah dilakukan oleh Warda (2016) dengan judul Hubungan Persepsi Mutu Pelayanan Dengan Tingkat Kepuasan Pasien Puskesmas Perumnas Di Kota Kendari Tahun 2016. Hasil penelitian menunjukkan tingkat kepuasan sebesar 45\%. Persepsi empati dengan $\mathrm{OR}=2,594$ (95\%CI: $1,165-5,779)$ mempunyai hubungan yang signifikan dengan kepuasan pasien.

\section{KESIMPULAN}

1. Karakteristik responden pasien di RS. Pertamina Bintang Amin Bandar Lampung tahun 2018 sebagai berikut sebagian besar responden berumur 41 - 50 tahun berjumlah 69 orang $(57,5 \%)$, sebagian besar responden berjenis kelamin laki laki berjumlah 74 orang $(61,7 \%)$, sebagian besar responden berpendidikan rendah berjumlah 82 orang $(68,3 \%)$ dan sebagian besar responden mempunyai pekerjaan berjumlah 84 orang (70\%).

2. Kepuasan pasien di RS. Pertamina Bintang Amin Bandar Lampung tahun 2018 sebagian besar puas berjumlah 73 orang $(60,8 \%)$.

3. Dimensi pelayanan kesehatan di RS. Pertamina Bintang Amin Bandar Lampung tahun 2018 sebagai berikut Reliability sebagian besar baik berjumlah 73 orang $(60,8 \%)$, Assurance sebagian besar baik berjumlah 65 orang (54,2\%), Tangible sebagian besar baik berjumlah 69 orang $(57,5 \%)$, Empathy sebagian besar baik berjumlah 64 orang $(53,3 \%)$, responsiviness sebagian besar baik berjumlah 61 orang $(50,8 \%)$.

4. Keterkaitan antara dimensi mutu pelayanan kesehatan dengan kepuasan pasien sebagai berikut $p$ value Reliability yaitu $0,002, p$ value Assurance yaitu $0,001, p$ - 
value Tangible yaitu $0,014, p$ value Empathy yaitu $0,037, p$ value Responsiveness yaitu 0,006.

5. Berdasarkan hasil uji analisis dari kelima variabel pada dimensi pelayanan antara lain Reliability, Assurance, Tangible, Empathy dan Responsiveness didapatkan variabel Assurance paling dominan terkait dengan kepuasan pasien dan variabel Tangible sebagai variabel perancu.

\section{DAFTAR PUSTAKA}

Alwi, A. dkk. (2011). Analisis Mutu Pelayanan Kesehatan Ditinjau dari Aspek Input Rumah Sakit di Instalasi Rawat Inap RSU Haji Makassar. Jurnal MKMI, Vol 7 No. 1.

Al-Assaf, A. F. (2009). Mutu Pelayanan Kesehatan Perspektif Internasional. Jakarta: EGC.

Asmuji. (2013). Manajemen Keperawatan : Konsep dan Aplikasi. Yogyakarta: Ar-Ruzz Media

Hardianti, U., \& Amir, M. Y. (2013). Faktor yang Berhubungan dengan Mutu Pelayanan Antenatal di Puskesmas Pattingalloang Kota Makassar. Jurnal Administrasi dan Kebijakan Kesehatan Indonesia, 2(02).

Anjaryani, W. D. (2009). Kepuasan Pasien Rawat Inap Terhadap Pelayanan Perawat di RSUD Tugurejo Semarang (Doctoral dissertation, UNIVERSITAS DIPONEGORO). (diakses 14 Maret 2012 dari http//eprints.undip.ac.id/23824/ 1/WIKE_DIAH_ ANJARYANI.pdf),

Arisutha, D. (2005). Dimensi Kualitas Pelayanan. Jakarta: Penerbit Gramedia Pustaka.

Budiastuti. 2002. Faktor-Faktor Dalam Meningkatkan Kepuasan Pasien Di Rumah Sakit. (diunduh pada tanggal 2 januari 2018 dari http// www//klinis.wordpress//kepuas an pasien terhadap pelayanan keperawatan).

Budi, S. C. (2011). Manajemen Unit Kerja Rekam Medis. Yogyakarta: Quantum Sinergis Media.

Dharma, K. K. (2011). Metodologi Penelitian Keperawatan: Panduan Melaksanakan Dan Menerapkan Hasil Penelitian. Jakarta: Trans Info Media.

Hardiansyah. (2011). Kualitas Pelayanan Publik. Yogyakarta: Gaya Media.

Hasibuan, S. P. Malayu. (2013). Manajemen Sumber Daya Manusia. Edisi Revisi. Jakarta: Penerbit PT. Bumi Aksara.

Hatta, G. R. (2009). Pedoman Manajemen Informasi Kesehatan Di Sarana Pelayanan Kesehatan. Jakarta: Universitas Indonesia.

Herlambang, Susatyo. (2016). Manajemen Pelayanan Kesehatan Rumah Sakit. Yogyakarta: Gosyen Publishing

Indarjati, A., (2001). Kepuasan Konsumen. Pranata

J. Supranto. (2008). Statistik Teori dan Aplikasi, edisi ketujuh. Jakarta: Erlangga

Junadi, P. (2004). Seminar Survey Kepuasan Pasien Di Rumah Sakit Di RSAPD Gatot Subroto Jakarta

Kementerian Kesehatan RI. (2004). Undang-Undang RI Nomor 29 Tahun 2004 Tentang Praktik Kedokteran. Jakarta.

Kementerian Kesehatan RI. (2009). Undang-Undang RI Nomor 44 Tahun 2009 Tentang Rumah Sakit. Jakarta.

Kementerian Kesehatan RI. (2009). Undang-Undang RI Nomor 23 tahun 1992 tentang Kesehatan. Jakarta

Kementrian Kesehatan RI., (2014). Undang-Undang 36 Tahun 2009 tentang kesehatan. Jakarta

Kementrian Kesehatan RI. (2012). Profil Kesehatan Indonesia Tahun 2012. Jakarta

Kotler, P., Armstrong, G., \& Susanto, A. B. (2008). Alih Bahasa: 
Benyamin Molan; Penyunting:

Bambang Sarwiji, SE;

Manajemen Pemasaran, edisi 12 Jilid 2. Jakarta: PT. Indeks.

Lawalata, A., Umboh, J. M. L., \& Rampengan, S. (2016). Hubungan Antara Mutu Pelayanan Dengan Kepuasan Pasien Di Ruang Rawat Inap Penyakit Dalam RSU Bethesda Gmim Tomohon. Community Health, 1(2).

Margaretha. (2003). Kualitas Pelayanan: Teori dan Aplikasi. Jakarta: Mandar Maju.

Martul, S. (2004). Implementasi Dimensi Kualitas Pelayanan Konsumen. Jakarta: Sinar Grafika

Melinda, S. P., \& Meiyanto, I. S. (2011). Pengaruh Iklim Kerja Organisasi Dan Komitmen Organisasi Terhadap Mutu Pelayanan Kesehatan Pada Perawat Rumah Sakit Umum Pusat Haji Adam Malik Medan (Doctoral dissertation, Universitas Gadjah Mada). (dikases 3 Januari 2018 dari etd.repository.ugm.ac.id/index.p hp?mod=penelitian_detail\&sub.. .act).

Meutia Dewi. (2016). Pengaruh Kualitas Pelayanan Terhadap Kepuasan Pasien Pengguna BPJS pada Rumah Sakit Rehabilitasi Medik Kabupaten Aceh Timur. (diakses 2 januari 2018 dari https://media.neliti.com/.../196 982-ID-pengaruh-kualitaspelayanan-terhadap-kep.pdf)

Muninjaya, I Gede. (2014). Manajemen Mutu Pelayanan Kesehatan. Jakarta: EGC.

Notoatmodjo, S. (2012). Metodologi Penelitian Kesehatan. Jakarta: Rineka Cipta.

Nursalam. (2016). Manajemen Keperawatan Aplikasi Dalam Praktik Keperawatan Profesional. Jakarta: Salemba Medika.

Parasuraman, A., Zeithaml, V. A., \& Malhotra, A. (2005). ES-QUAL: A Multiple-Item Scale For
Assessing Electronic Service Quality. Journal of service research, 7(3), 213-233.

Pohan, I. S. (2013). Jaminan Mutu Pelayanan Kesehatan: Penerapannya Dalam Pelayanan Kesehatan. Kesaint Blanc.

Putri, B. S., \& Kartika, L. (2017). Pengaruh Kualitas Pelayanan Bpjs Kesehatan Terhadap Kepuasan Pengguna Perspektif Dokter Rumah Sakit Hermina Bogor. Jurnal Riset Manajemen dan Bisnis (JRMB) Fakultas Ekonomi UNIAT, 2(1), 1-12.

Putri, N. R. G. (2010). Penentuan Tarif Jasa Rawat Inap Dengan Mempertimbangkan Metode Activity Based Costing Di Rsud Pandan Arang Boyolali. (diakses 2 januari 2018 dari https://digilib.uns.ac.id/.../Pene ntuan-Tarif-Jasa-Rawat-InapDengan-Mempertimbangkanmetode-activity-based-costing)

Raffi, F. (2010). Nurse Caring In Iran and As Relationship With Patient Satisfaction. Australian Journal of Advanced Nursing, 26(2).

Rangkuti, F. (2006). Analisis SWOT Teknik Membedah Kasus Bisnis. Jakarta: Gramedia Pustaka Utama.

Supartiningsih, Sholichah. (2015). Pengaruh Kualitas Pelayanan Ditinjau Dari Dimensi Tampilan Fisik, Keandalan, Daya Tanggap, Jaminan, dan Empati Terhadap Kepuasan Pasien Rumah Sakit Sarila Husada Sragen. (diakses Januari 2018 dari mmr.umy.ac.id/pengaruhkualitas-pelayanan-terhadapkepuasan-pasien-rumah-sakits).

Supardi. (2008). Hubungan Antara Persepsi Mutu Pelayanan Pengobatan Dengan Kepuasan Pasien di Balai Kesehatan Karyawan Rokok Kudus. Universitas Diponegoro Semarang. (diakses 3 Januari 2018 dari eprints.undip.ac.id/18657/1/SUP ARDI.pdf). 
Suparyanto. (2013). Kehandalan

(Reliability) Mutu Pelayanan Kesehatan. (diakses 3 Januari 2018 dari drsuparyanto.blogspot.com/2013/ 01/keandalan-reliability-mutupelayanan.html).

Supranto, J. (2001). Pengukuran Tingkat Kepuasan Pelanggan untuk Menaikkan Pangsa Pasar. Jakarta: Rineka Cipta.

Tim Penyusun. (2015). Panduan Penyusunan Skripsi dan Tesis. Fakultas Kesehatan Masyarakat Universitas Malahayati. Bandar Lampung.

Tjiptono, F., \& Chandra, G. (2011). Service, quality \& satisfaction. Yogyakarta: Andi Offset.

Warda, A., Junaid, J., \& Fachlevy, A. F. (2016). Hubungan Persepsi Mutu Pelayanan dengan Tingkat Kepuasan Pasien Puskesmas Perumnas di Kota Kendari Tahun 2016. Jurnal Ilmiah Mahasiswa Kesehatan Masyarakat, 1(3).

Wibowo, A. (2014). Metodologi Penelitian Praktis Bidang Kesehatan. Jakarta: Rajawali Pers 